\title{
El lado oscuro de la plata. \\ La vida en los reales mineros novohispanos \\ a finales del siglo XVIII
}

Para Verónica

Eduardo Flores Clair

DEH-INAH, México

Las expresiones culturales de los pueblos mineros nos permiten estudiar los elementos que conformaron su perfil. El análisis de sus formas de socialización y de los recursos que tenían a su alcance para su placer, nos lleva a identificar el rostro de las pasiones y revela los mundos subterráneos. El propósito de este estudio es presentar algunos apuntes e ideas sobre ciertas prácticas cotidianas que, ante los ojos del poder civil y religioso, eran consideradas reprobables.

Los pueblos mineros, que surgían esporádicamente en las escarpadas montañas, eran el escenario de una forma de vida peculiar, la cual reunía distintas manifestaciones culturales que articulaban la interacción social. En ese sentido cabe preguntarse: ¿cuáles eran las formas de diversión en los centros mineros?, ¿en qué medida participaban los distintos sectores sociales en las fiestas públicas y religiosas?, ¿cuál fue el papel del Estado y la Iglesia en la promoción y freno de las diversiones?, ¿qué importancia tenían los juegos de azar en la vida de las comunidades mineras?, ¿cómo se fue construyendo la identidad minera a partir de ciertos rasgos que la distinguían de otras organizaciones sociales?, ¿de qué manera los entretenimientos propiciaron las relaciones íntimas entre hombres y mujeres?. Es evidente que no tendremos respuestas contundentes para resolver estos enigmas; sin embargo, intentaremos dar algunas pistas que arrojen luz sobre estos problemas.

\section{La ciudad de los sueños}

Parece ser que todos los vicios y desgracias tenían su origen en el descubrimiento de los yacimientos mineros. Las crónicas y documentos históricos describen con detalle el deseo perverso de unos hombres que viajaban, de un lado a otro, a lo largo del territorio, en busca de fabulosas 
e indescriptibles ciudades, pues creían en la existencia de pueblos edificados con ricos minerales y piedras preciosas; los hombres hablaban de lugares maravillosos con montañas plateadas, lagos de mercurio, peces dorados que viajaban por arroyos cristalinos y pueblos colosales con puertas de esmeraldas.

A finales del siglo XVIII, las leyendas medievales sobre las ciudades de Cíbola y Quivira ${ }^{1}$ habían enraizado en el imaginario colectivo y, de manera diversa, se difundían por medio de las "hablillas"; todos los pobladores, aún los de parajes más remotos, se enteraban de la "voz de la bonanza", la cual tenía la fuerza suficiente para mover montañas.

Podemos suponer que una buena parte de los reales mineros tuvo su fuente de inspiración en el imaginario social. Los buscones - buscadores de minerales - contaban historias que revelaban — para todos los creyentes- sitios fantásticos colmados de inmensos tesoros. Las narraciones tenían un carácter y significado distinto en cada uno de los estratos sociales pero siempre eran relatos que encendían la imaginación y trazaban puentes con la invención de los deseos; narraciones que cambiaban con el tiempo y con la manera de ser y pensar de los novohispanos. Dichas historias brindaban la oportunidad de visitar o imaginar las ciudades mineras, que en su gran mayoría habían sido descubiertas por la casualidad, la fortuna, la ficción, el mito o la necesidad de viajar por el tiempo. ${ }^{2}$

Durante años y años, las "voces vulgares" repitieron sin cesar un puñado de cuentos sobre los enigmas de las montañas y los misterios que rodeaban a las minas. En algunas regiones, el mito fundacional de las vetas estuvo relacionado con hechos religiosos o sobrenaturales; en otros pueblos fue atribuido a hechos verídicos, pero imposibles de comprobar. Con frecuencia, en los relatos aparecían hermosos paisajes habitados por mujeres de una enorme belleza, quienes invitaban al viajero a su morada para colmarlo de riquezas y placeres. En otras narraciones, los protagonistas transitaban por caminos secretos; casi siempre, por la noche, las montañas ardían y mostraban — sólo a los elegidos - sus crestas plateadas y confe-

1 Para las leyendas medievales véase Gurría Lacroix, Jorge:”La minería, señuelo de conquista y fundaciones en el siglo XVI novohispano", en La minería en México, México, 1978, págs. 39-65. Weckmann, Luis: La herencia medieval de México, 2 vols. México, 1984.

2 Entre otros títulos pueden verse Corona Núñez, José: Rincones michoacanos; leyendas y breves datos históricos de algunos pueblos de Michoacán, s. 1., 1938; Lanuza, Agustín: Romances, tradiciones y leyendas guanajuatenses, 2a. ed., México, 1941; Rublúo Islas, Luis: Tradiciones y leyendas hidalguenses, Pachuca, Hgo., 1976; López Riesgo, Alfonso:La maravillosa tarasca y el prodigioso tesoro de Tayopa, Hermosillo, Son., 1986. 
saban el secreto de sus entrañas, en algunas de las cuales guardaban celosamente elefantes de plata. ${ }^{3}$ En algunas ocasiones, el velo que cubría a las ciudades encantadas era recorrido por algún personaje terrenal como el "indio aparecido", quien poseía gallos de plata y súbitamente desaparecía en las sombras de la noche, cuando los mortales intentaban indagar su procedencia. ${ }^{4}$

Dichas historias incorporaban en sus argumentos la idea cristiana de la buena fortuna para la gente humilde, devota y "de buen corazón". En algunas leyendas, el protagonista solía ser un arriero infatigable, campesino agradecido o buscón aventurero; los protagonistas tenían como elemento común la pobreza. Por ello, un ser mágico premiaba la humildad con los dones de la riqueza. Por ejemplo, las minas de Tlalpujahua fueron descubiertas por unos pastores pobres de la hacienda de Tepetongo, los cuales "habiendo prendido fuego una noche en el cerro nombrado del Gallo, para protegerse del frío, a la mañana siguiente, despertaron y hallaron plata derretida". ${ }^{5}$

Podemos decir que, a lo largo de la época colonial, las leyendas fueron un poderoso motor que estimuló la exploración e inversión en territorios agrestes $\mathrm{y}$, de manera paralela, despertaron en una muchedumbre el deseo de deambular entre cerros y piedras en busca de minerales ocultos. La credibilidad de los relatos se propagó ampliamente sin encontrar límites de creencias ni geográficos. A este respecto, en 1800 el justicia de Autlán, Anastasio González, escribió que las "voces" [rumores] de minas ricas, tapadas y ocultas, eran muy frecuentes entre los indios y habían acarreado muchos engaños. En esa región era muy conocida la historia sobre la mina del cerro de Cocama, el cual "ha sonado, según dicen, hasta algunos lugares de España, pues muchos hombres han venido de distantes lugares en busca de ella". ${ }^{6}$

Como una trampa a la imaginación y al deseo de fortuna, la explotación de las minas implicaba aventurarse por tierras extrañas, zonas de un mundo ajeno y subterráneo, lugares misteriosos, ocultos y secretos que no pertenecían a los hombres, sino al rey de las profundidades. No obstante, los mitos sobre las minas constituían parte de las distintas concepciones

3 Gámiz, Everardo: Leyendas durangueñas y biografías de los hombres más célebres del estado de Durango, México, 1930.

4 Porras Muñoz, Guillermo: El nuevo descubrimiento de San José del Parral, México, 1988.

5 Archivo General de la Nación, México (en adelante AGN), Historia, vol. 73, exp. 17, 1789.

6 AGN, Minería, vol. 31, exp. 8, 1800. 
culturales de una comunidad de "iniciados", dispersos por el territorio y empeñados en una búsqueda de más de tres siglos. También dichas crónicas eran la guía y orientación, relato e historia, reconocimiento y conquista, descubrimiento y colonización de nuevas tierras.

A finales del siglo XVIII, según los oficiales reales, los pueblos mineros estaban habitados por indios, españoles, mestizos, mulatos, negros y castas; dichas categorías eran utilizadas con el fin de reducir la complejidad social. Claramente sabemos que cada uno de estos estamentos encerraba una amplia gama de grupos étnicos diferentes, los cuales acrecentaban su diferenciación por la situación geográfica, formas de vida, relaciones de vecindad, lengua, recuerdos trasmitidos por la tradición, costumbres y otros elementos. Los pueblos mineros eran una especie de unidad multicultural constituida por un conjunto de hechos materiales, discursos y códigos morales que le daban un sentido peculiar al desarrollo social. En otras palabras, dicha amalgama social adquirió modos culturales específicos según cada una de las regiones y según las influencias y tradiciones aportadas por cada uno de los componentes raciales en la interacción social y circularidad cultural.

A pesar de todas las diferencias, podemos intuir la existencia de un proceso de construcción de una afinidad social, caracterizado por una tendencia acelerada de hábitos culturales comunes de tipo mestizo. ${ }^{7}$ Dicha tendencia impuso sus valores culturales sobre el lento intercambio sexual entre los distintos grupos raciales. Es decir, las formas mestizas culturales adquirieron una mayor dinámica en las congregaciones mineras, debido a los vínculos y convivencias raciales; de este modo, el espacio social encontró una forma de evolución mediante el trabajo concreto de la explotación y beneficio de los minerales y a través de ciertas prácticas donde la población encontró algunos nexos para construir su identidad. Por su parte, el mestizaje biológico rompió, en forma paulatina, las barreras de las rígidas estructuras sociales y del comportamiento (relativamente) endogámico de la mayoría de los grupos étnicos. ${ }^{8}$

7 En torno al problema de la cultura mestiza, véase Claudio Esteva Fabregat "Población y mestizaje en la ciudades de Iberoamérica: siglo XVIII" en Revista de Indias, vol. XXXII, Madrid, enero-diciembre de 1972, págs. 551-604.

8 Carmagnani, Marcelo: "Demografía y sociedad: la estructura social de los centros mineros del norte de México 1600-1720" en Historia Mexicana, vol. XXI, núm. 3, México, enero-marzo de 1972, págs. 419-459; Brading, David A.: "Grupos étnicos; clases y estructura ocupacional en Guanajuato (1792)" en Ibídem, págs. 460-480; Pérez Toledo, Sonia y Klein, Herbert S.: "La población de la ciudad de Zacatecas en 1857" en Historia Mexicana vol. XLII, núm. 1, México, julio-septiembre de 1992, págs. 77-102. 
En forma general, la construcción de los pueblos mineros fue acelerada: de la noche a la mañana, los reales aumentaban su vecindario. En muchos casos, el caserío solía tener una vida efímera y un destino triste pues las parvadas de trabajadores cambiaban de clima con las estaciones del año; de montaña en montaña, buscaban ricos minerales para mejorar sus condiciones de vida. ${ }^{9}$ Debido a ello, muchos de los reales no pasaron de ser simples "escarbaderos" y algunos gozaron de espectaculares bonanzas momentáneas, arruinándose por el súbito agotamiento de las vetas. De los pueblos abandonados sólo quedaron agujeros en la tierra, sombras de los olvidados ancestros y un puñado de leyendas.

La historia sublime de los metales brillantes y de la formación de inmensas fortunas, estaba ceñida con una realidad áspera y llena de conductas consideradas como perversas. Por lo general, los pueblos mineros perdían su lustre y notoriedad debido a la composición y prácticas sociales. En este sentido, el paisaje descrito por Francisco Mourelle, que visitó las famosas minas de Guanajuato en 1790 atraído por la curiosidad de la enorme producción de plata, nos permite tener una imagen de algunas de las conductas más reprobables del centro minero. Mourelle escribió que los minerales eran extraídos por "avaricia, ambición y codicia"; los hombres, empresarios y trabajadores, eran movidos por el afán, la pasión, la miseria y el apetito de poseer riquezas. Para conseguir su objetivo, llegaban a desafiar las leyes divinas, su propia naturaleza y a efectuar ciertos hechos "impronunciables". En cierta medida, el trabajo minero degradaba a los sujetos racionales, era realizado principalmente por hombres incultos, toscos y groseros, "esqueletos vivientes que llevan una vida triste". A pesar de la brillantez de la plata, Mourelle añadió una frase lapidaria: en Guanajuato vive la "escoria de la humanidad". ${ }^{10}$

Los viajeros no fueron los únicos que criticaron en su discurso los horrores y desdichas provocadas por el trabajo en las minas. Las comunidades indígenas que estuvieron condenadas al repartimiento, dejaron valiosos testimonios respecto a la terrible situación que padecieron. Por ejemplo, en 1757, el gobernador de Tulancingo apeló a las autoridades virreinales con el fin de que los indios de esa comunidad no prestaran sus servicios en la hacienda de beneficio del Salto, en Real del Monte. Entre

9 "Informe de Sombrerete de las minas de Pabellón y Vetanegra" en Colección Genaro García, Austin, Texas, rollo 166.

10 "Viaje de don Francisco Mourelle a las minas de Guanajuato en noviembre de 1790" en Isauro Rionda Arreguín, comp.: Testimonios sobre Guanajuato, Guanajuato, 1989, págs. 103-136. 
otras razones, expuso que los hombres eran maltratados y los obligaban a ir a lugares de "temperamento frío", de tal modo que los indios veían quebrantada su salud y al poco tiempo regresaban a sus pueblos a morir.

Además, al ausentarse, los indios desamparaban a sus mujeres e hijos, abandonaban sus sementeras, dejaban de contribuir con el tributo y no cumplían con los ritos y ceremonias religiosas. El trabajo de la hacienda era muy "recio" y no para gente "bisoña", pues al realizarlo de manera imperfecta, los mayordomos y mandones azotaban y encarcelaban a los indígenas. Asimismo, solían sufrir frecuentes enfermedades y accidentes fatales. Y sin duda, todos aquellos que iban a trabajar en la hacienda del Salto se "pervertían"."1

Las autoridades escribieron que los mineros eran soberbios, se tenían en alta estima y despreciaban a los de su entorno. Inclinados a sembrar chismes, enredos y engaños, mostraban falta de rectitud y un apetito insaciable por perturbar el orden; sus acciones eran de una maldad extrema y corrompían las costumbres. Por la agresividad y violencia desarrollada, fueron catalogados como altaneros, desobedientes, atrevidos, insolentes, descarriados y con suma falta de respeto a las órdenes de los superiores. ${ }^{12}$

Podríamos aventurar la hipótesis de que las autoridades utilizaron todos estos adjetivos, creencias y juicios con la finalidad de construir una imagen maligna y contraponerla a otras formaciones sociales. Pero más allá de la estricta normativa y estrechos principios morales, las ideas mostraban parte de una realidad incomprensible para muchos. Por diversas prácticas sabemos que las sociedades mineras dieron muestra de una forma de vida distinta, construida con base en ciertos valores culturales diferentes de los practicados en otros pueblos y ciudades; y opuestos a las idealizadas y obedientes comunidades indígenas. Muchos de los estilos de la vida minera, en cierto sentido, resultaban indescifrables y peligrosos, por estar constituidos por una muchedumbre casi ingobernable.

También es probable que, con base en estos testimonios y prácticas inteligibles, muchos escritores de la época contribuyeran con un discurso peyorativo y denigratorio contra los centros mineros. En distintos textos encontramos que dichos lugares eran considerados como centros de vicio, parajes donde habitaba el diablo, teatros de crueles crímenes, escenarios de escandalosas conductas extraviadas en el juego, el robo, la embriaguez,

11 AGN, Minería, vol. 148, exp. 11, 1757.

12 Los conceptos citados aparecen con frecuencia en diversos documentos. Como ejemplo representativo puede consultarse AGN, Historia, vol. 133, exp. 1. 
las riñas, sitios donde se corrompía y pervertía a los naturales con prácticas sexuales relajadas y viviendo en un desorden generalizado, producto de una multitud de vagos y hombres perdidos que dañaban las costumbres de las poblaciones. Cabe señalar que dichos discursos no estaban del todo errados ya que, años después, los mismos hombres, con desamparo espiritual y material, se convirtieron en los principales grupos contestatarios y formaron parte activa de las tropas insurgentes.

\section{La ciudad del vicio}

Como apuntamos, los reales eran considerados - por funcionarios y eclesiásticos - centros de vicio, lugares donde se perdían las buenas conciencias y se impugnaban las costumbres ancestrales. Este tipo de juicios se hacía, principalmente, por los excesos en las diversiones públicas, los juegos de azar, el alto consumo de bebidas embriagantes y las conductas sexuales relajadas. En este aspecto, José Perfecto, cura del real de Nuestra Señora del Rosario, en Sonora, escribió que en el centro minero había tal desorden en toda la sociedad que una buena parte vivía en la infelicidad "y muchos dicen que estamos en Francia, por el libertinaje de las costumbres, y por tan malos ejemplos de las cabezas". ${ }^{13}$

Quizá podamos encontrar una posible explicación de esta forma de vida llamada "libertina", por tres factores: en primer lugar, el gran desarraigo de los pueblos mineros. La constante movilidad, les permitía tener frecuentes contactos e intercambios de valores culturales, lo que posibilitaba una mayor experimentación con los estilos de vida de una muchedumbre. En segundo lugar, los pueblos mineros gozaron de una alta capacidad económica y este hecho los distinguió de la mayoría de los centros urbanos de la Nueva España; los cuantiosos caudales que circulaban en los reales brindaban la oportunidad de establecer negocios redituables de divertimiento, que fungían como un complemento indispensable de la producción minera. De hecho, los habitantes poseían un alto poder de consumo, que aprovechaban para deleitarse con los cuantiosos abastos de mercancías y participar de las placenteras transgresiones. Por último, como ya se ha mencionado, la mezcla racial permitía la formación de comunidades domésticas diversas, las cuales deambulaban con sus valores sociales entre

13 AGN, Inquisición, vol. 1372, exp. 7, 1810. 
los cerros y la interacción social provocaba, a largo plazo, la transformación de las costumbres.

A lo largo de la época colonial, por medio de la legislación y doctrina cristiana, las autoridades políticas y eclesiásticas intentaron crear una especie de "dique moral" para frenar los desmanes en los pueblos mineros. Para conseguir tal objetivo, ambas instancias conjuntaron sus intereses y unieron sus recursos - hasta cierto punto - para combatir a todas aquellas formas de vida y prácticas sociales que consideraban reprobables, ilegales, pecaminosas y delictivas.

En este terreno, es bien sabido que los Borbones mostraron especial interés por regular la vida de la sociedad novohispana; sus autoridades impulsaron un proyecto de control social que abarcó los ámbitos de administración económica, preservación del orden y salvaguarda de los valores espirituales. De esta manera, la hacienda pública, apoyándose en distintas oficinas, reguló el comercio y circulación de los naipes, gallos, aguardiente de caña, tabaco, pulques, lotería y otras rentas, para lo cual se renovaron y crearon distintos estancos. Las transgresiones fueron atendidas por los cuerpos de policía y tribunales especiales. Y el "pasto espiritual" fue materia de la Iglesia y sus miembros. ${ }^{14}$

Las autoridades civiles y religiosas, por medio de la práctica administrativa, confeccionaron un vasto cuerpo normativo, el cual delimitó la frontera entre la permisividad y lo prohibido, frontera por demás tenue como un velo. Cabe agregar que, entre telones, la Corona, con ayuda de la iglesia, se convirtió en el mayor beneficiario de los llamados vicios; dichos recursos económicos tuvieron como fuentes la producción, circulación, consumo y multas impuestas a los transgresores. Sin embargo, el monopolio estatal del vicio dejó hendiduras que algunos grupos aprovecharon en beneficio propio: construyeron caminos clandestinos y abrieron ciertos espacios para burlar la vigilancia y mantenerse fuera del ámbito legal. ${ }^{15}$

14 Un estudio de tipo legal sobre estos problemas es el de Viqueira Albán, Juan Pedro: ¿Relajados o reprimidos? Diversiones públicas y vida social en la ciudad de México durante el siglo de las luces, México, 1987.

15 En 1804, el arzobispo de la ciudad de México, Francisco Javier de Lizana, publicó una carta pastoral con el fin de delimitar la frágil frontera entre los juegos permitidos y de azar. Teniendo como base los principios de la religión y las leyes civiles, Lizana escribió un detallado estudio que dejó constancia de la tolerancia que mantenían las autoridades civiles y religiosas sobre los excesos en la vida mundana. Ambas instancias no pretendían prohibir totalmente las distracciones pecaminosas, porque había muchos intereses involucrados, además de los distintos procesos productivos que estaban encadenados a la vida libertina. Lizana y Beaumont, Francisco Xavier de:Carta pastoral en la que el ilustrísimo señor ..., arzobispo de México instruye a los fieles de su arzobispado sobre el juego y los arreglos que en él se hallan, México, Imprenta de Mariano Zúñiga y Ontiveros, año de 1804, 43 págs. 
Durante las últimas décadas del siglo XVIII, existió un elevado número de diversiones permitidas, las cuales se diferenciaban por su naturaleza, costo económico, intención y espacios sociales que ocupaban. Sin pretender una relación exhaustiva, mencionaremos por ejemplo el juego de la sortija, el de los tejos, las alcancías y el cándido entretenimiento de la "maroma", el cual era una especie de volantín que instalaban temporalmente en las plazas de los pueblos. Asimismo, los habitantes gozaban, con cierta frecuencia, de las representaciones teatrales, efectuadas en el atrio de la iglesia, en la plaza y hasta en el panteón, siendo las obras puestas en escena por actores profesionales o espontáneos. Algunas comedias eran pieza clave en el proceso de evangelización y otras escenificaban temas profanos. ${ }^{16}$

Pero sin duda, la reina fue la fiesta brava, que adquirió un arraigo profundo. Las corridas de toros fueron un mecanismo significativo de interacción social, cuya tradición se remontaba hasta los primeros años de la conquista, y llegaron a gozar de gran aceptación. Se realizaban para celebrar el nacimiento y cumpleaños de los monarcas, el aniversario del santo patrono, la llegada de los virreyes y otros festejos similares. Los toros se alternaban con un buen número de espectáculos de distinta naturaleza como desfiles, mascaradas, maromeros, fuegos artificiales, comedias, loas, danzantes, músicos, carreras de liebres, cómicos, peleas de gallos y pirámides, entre otros.

En la medida de lo posible, todos los sectores sociales participaban de la fiesta taurina; algunos realizaban cuantiosos aportes o simplemente pagaban su boleto de entrada para acomodarse en algún rincón del coso. Hombres y mujeres se disputaban los asientos, desde los humildes petates, pasando por los bancos y sillas, hasta los taburetes de terciopelo carmesí, ocupados por las personas de mayor lustre. Las fiestas eran fastuosas y de gran pompa, se tiraba la casa por la ventana; por esta razón, las celebraciones requerían de importantes recursos económicos para efectuarse. En el caso de las corridas ofrecidas a la llegada del virrey conde de Gálvez, el Tribunal de Minería tuvo que desembolsar la cuantiosa cantidad de 2.843 pesos, con el fin de obtener un palco y asistir a las funciones. ${ }^{17}$

En 1790, con motivo de la proclamación de Carlos IV, en distintas ciudades del reino tuvieron lugar magnas corridas de toros. En el caso de

16 Las críticas de teatro se difundían a través de los periódicos de fines del siglo XVIII, véase por ejemplo la Gazeta de México.

17 AGN, Minería, vol. 41, exp. 1, 1789. 
Guanajuato, la fiestas dieron inicio el 27 de diciembre y con tal motivo se levantó un monumental tablado, construido con una riqueza exquisita, para demostrar el poder minero. La diputación local del gremio montó lo que sería quizá la primera exposición minera en Nueva España, en la que se exhibieron las diferentes máquinas empleadas en la extracción y beneficio de minerales. La celebración comenzó con el paseo del pendón por varios días y durante los actos, el pueblo recibió una fabulosa cantidad de monedas de oro, plata y cobre acuñadas con el busto de Su Majestad e imágenes simbólicas del cuerpo de minería. Las fiestas continuaron con espléndidos banquetes para perpetuar en la memoria tan especial acontecimiento.

Por nueve días consecutivos, la fiesta de los toros llamó la atención de los habitantes; la Plaza de San Diego — en el corazón de Guanajuatofue elegida como recinto para sacrificar a los toros y en las corridas participaron toreros de a pie y a caballo, distribuyéndose luego la carne de los ciento ochenta bovinos lidiados entre algunas instituciones de caridad, con el fin de alimentar a los pobres. Después de las corridas, los asistentes disfrutaban de la música y del permiso para bailar hasta las diez de la noche. ${ }^{18}$

De hecho, los espectadores tenían la costumbre de prolongar la fiesta brava hasta la madrugada; la música invitaba a bailar a hombres y mujeres, dando oportunidad a las danzas pecaminosas y aprovechando la oscuridad para perderse entre los rincones ocultos de los tablados. La venta de pulque, chinguirito y otras bebidas embriagantes, propiciaba contundentes borracheras y riñas de consecuencias fatales. La convivencia de hombres y mujeres creaba un ambiente favorable para adelantar los placeres del matrimonio y la prostitución. Por estas acciones reprobables, las corridas de toros fueron duramente criticadas en distintas épocas y llegaron hasta a suspenderse. Además, el discurso modernizador ilustrado las atacó de forma despiadada, por considerarlas un espectáculo digno de los pueblos más atrasados y bárbaros. En este contexto, José Joaquín Fernández de Lizardi, con su mordaz estilo, señaló que "los hombres son más feroces que las bestias", porque los espectadores veían "expirar a los suyos sin compasión". ${ }^{19}$

18 Rangel, Nicolás: Historia del toreo en México: época colonial (1529-1821). México, 1924, págs. 132-133.

19 Fernández de Lizardi, José Joaquín: "La conferencia entre un toro y un caballo" en $E l$ Pensador Mexicano, Tomo III, núm. 14, México, 1814. 


\section{La ciudad del juego}

Las diversiones prohibidas o ilícitas encontraron en los reales una atmósfera propicia para su desenvolvimiento centrada en los juegos de azar como naipes, peleas de gallos, lotería, pelota, dados, biribis, billar y otros, que fueron entretenimientos cotidianos en los centros mineros. Cabe señalar que el conjunto de diversiones seguía muy de cerca el auge y decadencia de los ciclos económicos de la minería. Por los documentos revisados podemos afirmar que, en las épocas de bonanza, las autoridades adoptaron una política tolerante respecto a todo tipo de distracciones; por el contrario, en las etapas de depresión, endurecían sus acciones y los arrestos y castigos se multiplicaban. En los momentos de crisis, la pobreza de los desempleados generaba enorme preocupación entre las autoridades, quienes establecían una serie de mecanismos para frenar los posibles desórdenes. Sabían que la muchedumbre era una amenaza latente y en cualquier momento podía lanzarse a la senda de la violencia y el crimen.

A pesar de los castigos y restricciones, los sitios clandestinos de juego proliferaron en las regiones mineras y todo tipo de personas acudía a esos garitos. Por ejemplo, en el real de Zimapán, hacia finales del siglo XVIII, la diputación de minería local denunció al subdelegado ante el virrey, porque fomentaba "el vicio del juego de cartas". Los diputados se quejaron de que los operarios de minas y haciendas dedicaban mucho tiempo al juego y dejaban de asistir a las labores. Asimismo, los propietarios mineros perdían por causa del juego importantes caudales de los avíos, herramientas y utensilios indispensables en el trabajo y, en algunos casos, se quedaban sin liquidez para cubrir los salarios de los dependientes. En concreto, los naipes afectaban seriamente la marcha de los negocios mineros. ${ }^{20}$

Cuando llegó a Zimapán, Ramón de Jáuregui — subdelegado— se percató de la empresa redituable que podía realizar si tenía la capacidad de organizar y dirigir los centros de azar. Con este fin, estableció una serie de mesas de juego para los hombres "distinguidos y plebeyos" y para mejorar la supervisión, Jáuregui abrió garitos en las Cajas Reales, Alcaldía, en la casa de la Comunidad del Pueblo, a las afueras de la cárcel y en la morada de Mariano Arévalo, el sastre local. Las casas se diferenciaban por la calidad y status de las personas que concurrían: mientras los "arrastraderos" fueron reservados para los habitantes humildes, en las

20 AGN, Criminal, Vol. 7, exp. 3, 1797. 
Cajas Reales se fomentaba la exclusividad y sólo se permitía la entrada a "gentes decentes". De la misma manera, dichos antros se diferenciaron por el monto de las apuestas que en ellos se arriesgaban y el cobro que se hacía a los apostadores. ${ }^{21}$

Las casas de juego parecían baratillos, porque existía una enorme cantidad de implementos de trabajo, verduguillos, espadas, mangas, frazadas, enaguas, ceñidores, mascadas o pañuelos, cotones y otros. Los jugadores que empeñaban dichas prendas tenían como plazo máximo dos meses para recuperarlas; pero pasado dicho tiempo, los artículos se remataban al público y los propietarios no recibían demasía. A todos los jugadores que quedaban sin recursos y con una deuda crecida, Jáuregui los enviaba como trabajadores forzados a la mina de Lomo de Toro y las haciendas de beneficio de San Antonio y el Carmen, con el fin de desquitar las deudas.

En las minas y haciendas de beneficio era difícil cobrar esas deudas de juego, pues los barreteros tenían como salario 2 1/2 reales diarios, los peones "grandes" 2, los muchachos $11 / 2$ y los chiquillos uno. Mientras permanecían como forzados, los operarios solicitaban a los administradores préstamos para ciertos gastos, como la compra "de pan, semita y cigarros". Al finalizar la semana, los dependientes remitían el resto de los ingresos al subdelegado. En algunos casos, las madres o esposas de los presos le suplicaban algunos reales para solventar sus necesidades y para salir del paso, Jáuregui otorgaba la mitad del salario devengado, por lo cual el operario solía permanecer en las labores forzadas por varias semanas e inclusive meses, hasta saldar totalmente las deudas de juego.

La presencia de gente acaudalada en los reales generaba lugares muy exclusivos para los juegos de azar, frente a los de más baja estopa. En este caso, a finales del siglo XVIII, la escasez de trabajadores en Guanajuato provocó una redada general entre los supuestos "vagabundos". Las autoridades virreinales ordenaron detener a todos los hombres viciosos, holgazanes y tahures. Así, en octubre de 1796, Juan Antonio Riaño, coronel de los reales ejércitos, capturó a José Quiroz por el delito de vagancia y por ser un conocido coyme. La historia de Quiroz era muy parecida a otras: español de 59 años, minero matriculado del Real de Catorce y Guanajuato, por muchos años dedicado al ejercicio de su profesión sin mucho éxito; el desempleo lo aprovechaba para demostrar su habilidad en el juego de cartas, pero se distinguía por practicarlo con "personas decentes y de distinción".

21 Ibídem, vol. 6, exp. 6, 1789. 
Antes de la captura, Quiroz acondicionó una casa de juego en el sitio conocido como "el Hospital"; poco tiempo después, mudó su domicilio y alquiló una casa en "el callejón de Bueno". La clientela era muy selecta y sólo invitaba a personas de confianza, entre los que se encontraban el marqués de Rayas y algunos parientes de las familias acaudaladas Otero y Obregón. En la casa de juego se cuidaba que no hubiera desorden, trampas, ni fraudes y que las partidas se realizaran "con toda limpieza. El que tenía suerte para ganar, ganaba, y el que no, perdía". Los asistentes ganadores entregaban una gratificación de 8 o 10 pesos al dueño de la mesa de juego.

La casa tenía puertas "excusadas" para que entraran los jugadores con el mayor disimulo posible, evitando ser descubiertos por los justicias. Las puertas ocultas comunicaban la sala de juego con la vivienda del presbítero Antonio Fernández, quien mantenía una amistad muy cercana con Quiroz y además era uno de los asiduos concurrentes a las partidas de cartas, a las que invitaba a jugar a sus amigos más cercanos. Quiroz declaró que las puertas excusadas habían sido abiertas para el uso privado del sacerdote, con el fin de ofrecerle mayor comodidad y discreción. Las puertas tenían salida a distintas calles y simulaban incomunicación con la casa de juego y las habitaciones privadas del cura. Igualmente, las puertas evitaban la presencia de tahures, "mirones, fulleros y advenedizos con mala fe y alborotadores". En la mesa de juego estaba prohibida la entrada a los hijos de familia, cajeros o empleados y personas que dependían de otras. Con el fin de guardar el mayor secreto y discreción, el círculo exclusivo de jugadores manejaba una "contraseña", con la cual garantizaban sólo la asistencia de "personas de honor". Quiroz intentó librarse del confinamiento carcelario por medio del pago de una fianza y apeló al poder de sus clientela influyente, pero sus ruegos resultaron en vano y las autoridades lo condenaron al destierro. ${ }^{22}$

En general, el juego de naipes, con sus secretos, deudas y magia, iba acompañado del furor de las peleas de gallos ya que ambas diversiones eran complementarias y formaban una simbiosis. La población minera sentía una desmedida pasión por los gallos y esta afición abarcaba a los distintos estratos sociales, desde la gente más modesta hasta la élite más acomodada. Las peleas de gallos fueron una parte fundamental en las celebraciones de fiestas religiosas y profanas.

22 Ibídem, vol 385, exp. 2, 1796. 
En las zonas mineras existió un buen número de palenques. Hacia 1780, en Guanajuato había cuando menos tres, localizados en la Plaza Mayor y a las afueras de las minas de la Valenciana y la Cata. ${ }^{23}$ En el caso de Zacatecas, la Diputación de Minería fungió como asentista y controlaba las peleas de gallos, teniendo dependencias similares en Pánuco, Jerez, Sierra de Pinos, Nieves, Fresnillo, Sombrerete y Mazapil. Este hecho es una prueba evidente de que el negocio estaba muy extendido y resultaba redituable. ${ }^{24}$

Los gallos fueron más populares que las corridas de toros pues se jugaban todo el año y las peleas podían realizarse en cualquier rincón. Con frecuencia, los aficionados asistían al medio día a una "tapada de gallos" y, culminada la lucha de los emplumados, sin moverse del mismo lugar, la diversión solía prolongarse hasta la madrugada con una partida de cartas amenizada con música y baile. Los asientos en el palenque estaban divididos en tres grandes secciones: el presidio, las jaulas y el patio o valla. Los asistentes pagaban, generalmente, por once peleas de las llamadas "comunes", medio real o hasta 2 reales, dependiendo del lugar escogido, pero cuando se lidiaban "gallos de mar afuera" y tapadas pagaban el doble.

Es importante tener en cuenta que, por lo general, las peleas de gallos sólo tenían autorización para efectuarse los días festivos. Sin embargo, en 1783, Nicolás de Armas, asentista general del reino, con el fin de aumentar las ganancias y promover las apuestas, solicitó ante las autoridades virreinales que se permitiera el juego de gallos a lo largo de la semana en varias ciudades mineras, sobre todo en aquellas que tenían una población abundante y los habitantes no sólo se dedicaban a las labores propias de ese ramo. Después de una larga negociación entre distintas instancias, la Corona autorizó el juego diario en Guanajuato, Zacatecas, San Luis Potosí, Bolaños, El Rosario, Chihuahua y San Antonio. Pero quedaron prohibidas las peleas de gallos durante "los días de trabajo" en el resto de los centros mineros, para evitar la holgazanería entre los operarios.

La existencia de gallos a lo largo de la semana respondía a todos los intereses involucrados en el negocio, tales como granjeros, importadores, asentistas, comerciantes, apostadores, gravámenes fiscales y funcionarios públicos. Con el fin de cuidar el conjunto de intereses, las autoridades impusieron una multa de mil pesos para todas las peleas clandestinas; la

23 AGN, Gallos, vol. 2, exp. 12, 1803.

24 Ibídem, vol 2, exp. 3, 1804. 
infracción se distribuía por partes iguales entre la Real Cámara, el asentista general y el denunciante. ${ }^{25}$ No obstante las limitaciones, las peleas ilegales proliferaban, realizándose de manera clandestina en casas, calles, corrales y todo paraje aislado, donde la vigilancia fuera escasa. Entre quienes movían estos "negocios" a espaldas de los asentistas estaba un buen número de funcionarios reales. Sólo para dar un ejemplo, podemos decir que, en 1742, el oidor supernumerario de Guadalajara, Sebastián Calvo, fue destituído de su cargo porque no sólo participaba en las lides locales, sino que patrocinaba peleas en las minas de Sombrerete, con gallos de su propiedad. ${ }^{26}$

Las peleas de gallos, permitidas, daban inicio por lo regular al medio día; en algunos lugares se fijó como horario las tres de la tarde, con el fin de no interponerse con las obligaciones religiosas. Una vez que el público entraba a la plaza, el "gritón" anunciaba el combate, informaba el nombre, tamaño, peso, color y lugar de origen de los gallos; éstos habían sido previamente sometidos a un entrenamiento y armados con filosas navajas azules que relumbraban en los redondeles. Para dar más colorido, las armas se amarraban a las patas de los gallos con hilos brillantes de seda china; el triunfo dependía de la habilidad del amarrador y del soltador. Los corredores iban de una lado a otro levantando las apuestas. Y al grito de "cierren las puertas señores", comenzaba la lucha.

Según un espectador, Rafael Landívar, la pelea continuaba de esta manera: "vuelan las plumas por el vago viento; y del vientre rasgado y de las entrañas escápanse, al momento: y el luchador, habiendo ya regado el ancho coso, con raudal sangriento, sucumbe a su destino desgraciado. El vencedor [...] con alas de oro haciendo estremecer el arrogante pecho, exhala triunfante de la victoria del cántico sonoro". ${ }^{27}$

Además de los juegos de azar antes descritos, en los reales existieron otros entretenimientos para apostarle a la fortuna e intentar cambiar el futuro. Otro de los juegos de azar socorridos fue el juego de pelota, promocionado originariamente por los comerciantes vascos y sus dependientes; sin embargo, pronto se generalizó su gusto y adquirió fuerza entre la sociedad novohispana. Como bien dice Juan Pedro Viqueira, "el juego de pelota no desviaba a los comerciantes del primordial propósito de su vida: enrique-

25 Ibídem, vol. 1, exp. 4, 1795

26 Sarrablo Aguareles, Eugenio:El Conde de Fuenclara embajador y virrey de Nueva España, 2 ts., Sevilla, 1966, T. 2, págs. 226-227.

27 Landívar, Rafael: Rusticatio mexicana, libro decimoquinto, México, s.e., 1924. 
cerse. Altas apuestas corrían en la cancha, volviendo los encuentros mucho más emocionantes" ${ }^{28}$ La pelota fue considerada como un entretenimiento que ofrecía un rato de esparcimiento al espectador y, a la vez, un ejercicio que ayudaba a fortalecer la salud de los contrincantes. Sabemos que en una de las principales ciudades mineras, Zacatecas, fue construido "un magnífico juego de pelota que no deja de parecerse al de Oyarzun, provincia de Guipuzcoa, aunque no puede rivalizar con el modelo original". ${ }^{29}$

\section{Consideraciones finales}

Las utopías fueron el vehículo que permitió la búsqueda incansable de minerales preciosos, ideas que edificaron ciudades y escribieron historia. Las leyendas de El Dorado intensificaron la construcción de mitos y símbolos, lenguaje que sirvió para articular los deseos y esperanzas de la sociedad novohispana. En los reales, congregaciones de escarbadores reinventaron mundos imaginarios que desafiaban las fuerzas mágicas de las tinieblas, vencían a los espíritus malignos de las profundidades, arrancaban los tesoros ocultos en las entrañas de la tierra y conformaron una identidad cultural propia.

Resulta innegable que en la gran mayoría de los reales mineros, la sociedad - multiétnica - incorporó valores ajenos, elementos extraños y modos de vida distintos. Las diferencias permitían una cohesión, sostenida en una estructura socio-cultural mestiza. La amalgama racial de los valores morales, del espíritu e intelecto permeaba los estilos de vida, orientaba las perspectivas futuras, estimulaba la dinámica social y hacía aflorar la inconformidad. La disidencia se convertía fácilmente en herejía, la transgresión en excomunión, el delito en confinamiento. Las relaciones sociales permitidas, generaron de forma paralela un submundo clandestino, que tenía reglas independientes de las leyes civiles y religiosas.

Es evidente que la sociedad minera encontró en los espacios de divertimiento un ambiente propicio para la interacción social; ámbitos donde la gente común convivía, se comunicaba y trasmitía sus experiencias personales. En los días festivos, una vez cumplidas las obligaciones religiosas, el vecindario promovía la libertad y el disfrute de los placeres, irrumpía las

28 Viqueira, J.P.:"¿Relajados o reprimidos? ...”, pág. 246.

29 Langue, Frédérique: Mines, terres et société a Zacatecas (Mexique) de la fin du XVIIe siècle a l'indépendance, Paris, 1992, pág. 175. 
costumbres, creaba vínculos de parentesco y constituía una fuerza política. Este conjunto de hechos aislados le da sentido a la idea de los funcionarios y eclesiásticos de que en los reales mineros la gente se "pervertía". Desde nuestro punto de vista, la gente se alejaba de los patrones culturales tradicionales y creaba otros distintos, que en su momento fueron duramente atacados por los sectores que custodiaban "el buen orden y la moral social".

Las manifestaciones culturales en los pueblos mineros desgarraban los valores de las comunidades campesinas, constituían una nueva relación social frente a las sociedades tradicionales, pero, sobre todo, modificaban la naturaleza del trabajo. La explotación de los minerales imponía un tiempo y ritmo distinto, en el cual la disciplina laboral tenía como principio trabajar, producir y descansar, lo que contradecía los anteriores estilos de vida de los operarios.

Claro está que la riqueza generada por la explotación de los metales preciosos beneficiaba a grandes sectores sociales; pero es verdad que unas cuantas manos acumularon una desmedida opulencia, prestigio y poder. Esta situación explica, hasta cierto punto, los altos contrastes de la sociedad minera, la cual estaba constituida por la élite más acaudalada, pasando por una serie de grupos intermedios con un decente nivel de vida, hasta las personas más miserables.

El análisis de las distracciones nos revela el rostro de la convivencia y la segregación social. Es verdad que los entretenimientos provocaban una interacción entre los distintos grupos sociales, pero cada uno ocupaba un lugar determinado y jamás llegaban a mezclarse del todo, porque en dichos ámbitos existió una estructura jerárquica diferenciada por la clase, la etnia y el género. Cada una de las diversiones tenía sus reglas, protocolos y ritos, que los jugadores respetaban hasta el límite de la trampa y la transgresión pues tenían una especie de pacto expresado a través de un lenguaje, símbolos y códigos que sólo los enterados descifraban. Más allá de la frontera del discurso moralista del estado y la iglesia, los juegos de azar reinaban sobre las sensaciones indescriptibles que estimulaban el gozo y aventura, ambiente cargado de miradas turbadas e inquietantes, momentos de posibilidad para decidir y modificar el futuro, abundantes sueños de riqueza e incontrolables deseos de fortuna.

La tolerancia manifestada por la iglesia y las autoridades civiles en torno a las diversiones se puede explicar por el hecho de que eran partícipes, en cierta medida, de los beneficios económicos, control político y prestigio social que se desprendían de las mesas de juego. Ambas instancias 
fueron, hasta cierto grado, cómplices para promover relajamientos y libertinajes entre la sociedad y a la vez, en determinados momentos, impusieron políticas estrictas que, por otro lado, tuvieron un éxito relativo.

Por último, en el caso de las complejas relaciones sociales de los reales mineros, distinguimos un ambiente empapado de violencia, expresado a través de manifestaciones culturales e inspiraciones individuales. Aderezadas con la música, el canto y la danza, dichas expresiones estaban dotadas de los bajos instintos y sublime vocación, que desafiaban el temor a Dios y a las leyes de los hombres. En la vida minera, una muchedumbre errante promovía una conducta moral distinta y reflejaba su sed insaciable por las pasiones humanas. 